\title{
Amorphization of Thiamine Mononitrate: A Study of Crystallization Inhibition and Chemical Stability of Thiamine in Thiamine Mononitrate Amorphous Solid Dispersions
}

\author{
Seda Arioglu-Tuncil ${ }^{1,+}$, Adrienne L. Voelker ${ }^{1}$, Lynne S. Taylor ${ }^{2}$ and Lisa J. Mauer ${ }^{1, *}$ \\ 1 Department of Food Science, Purdue University, 745 Agriculture Mall Drive, West Lafayette, IN 47907, USA; \\ starioglu@beu.edu.tr (S.A.-T.); avoelke@purdue.edu (A.L.V.) \\ 2 Department of Industrial and Physical Pharmacy, Purdue University, 575 Stadium Mall Drive, \\ West Lafayette, IN 47907, USA; lstaylor@purdue.edu \\ * Correspondence: mauer@purdue.edu; Tel.: +1-765-494-9111 \\ + Current address: Gastronomy and Culinary Arts Department, Bitlis Eren University, Ahlat, \\ 13400 Bitlis, Turkey.
}

Received: 16 November 2020; Accepted: 4 December 2020; Published: 9 December 2020

check for updates

\begin{abstract}
This study investigated thiamine degradation in thiamine mononitrate (TMN):polymer solid dispersions, accounting for the physical state of the vitamin and the recrystallization tendency of TMN in these dispersions. Results were compared with those from solid dispersions containing a different salt form of thiamine (thiamine chloride hydrochloride ( $\mathrm{TClHCl}$ )). TMN:polymer dispersions were prepared by lyophilizing solutions containing TMN and amorphous polymers (pectin and PVP (polyvinylpyrrolidone)). Samples were stored in controlled temperature and relative humidity (RH) environments for eight weeks and monitored periodically by $\mathrm{X}$-ray diffraction and high performance liquid chromatography (HPLC). Moisture sorption, glass transition temperature $\left(\mathrm{T}_{\mathrm{g}}\right)$, intermolecular interactions, and $\mathrm{pH}$ were also determined. Similar to the TClHCl:polymer dispersions, thiamine was more chemically labile in the amorphous state than the crystalline state, when present in lower proportions in amorphous TMN:polymer dispersions despite increasing $\mathrm{T}_{\mathrm{g}}$ values, when environmental storage conditions exceeded the $T_{g}$ of the dispersion, and when co-formulated with PVP compared to pectin. When thiamine remained as an amorphous solid, chemical stability of thiamine did not differ as a function of counterion present (TMN vs. $\mathrm{TClHCl}$ ). However, storage at $75 \% \mathrm{RH}$ led to hydration of thiamine:PVP dispersions, and the resulting $\mathrm{pH}$ of the solutions as a function of thiamine salt form led to a higher chemical stability in the acidic $\mathrm{TClHCl}$ samples than in the neutral TMN samples.
\end{abstract}

Keywords: vitamin $\mathrm{B}_{1}$; thiamine; thiamine mononitrate; thiamine degradation; amorphous solid dispersion; physical stability; chemical stability; amorphous stability

\section{Introduction}

Thiamine is one of the most unstable vitamins: it is highly affected by heat, light, alkaline $\mathrm{pH}$, the presence of some food ingredients, radiation, inorganic bases, and processing treatments [1-3]. The susceptibility of thiamine to these conditions makes its delivery in processed, shelf-stable foods and dietary supplements challenging. When thiamine degrades, off-flavors develop due to formation of sulfur-containing degradation products $[2,4-6]$, thereby affecting not only vitamin label claims but also product acceptability as degradation proceeds. Therefore, understanding factors that affect the stability of thiamine in foods and dietary supplements is important for shelf-life, nutritional labeling, and food quality considerations. 
Two synthetic crystalline salt forms of thiamine, thiamine mononitrate (TMN) and thiamine chloride hydrochloride $(\mathrm{TCl} H \mathrm{HCl}$ ), have been extensively used for enrichment and fortification purposes in foods as well as in dietary supplements. These salt forms of thiamine possess different physicochemical features. For example, TMN is less soluble and less hygroscopic than $\mathrm{TClHCl}$; thus, TMN is commonly used to enrich dry food products, including flour, and in vitamin tablets and dietary supplements [7]. Although both $\mathrm{TMN}$ and $\mathrm{TClHCl}$ are distributed as crystalline ingredients, some processing methods and/or interactions with other food ingredients, such as polymers, may lead to the presence of thiamine in the amorphous state in many low or intermediate moisture products [8]. A study of $\mathrm{TClHCl}$ in solid dispersions found that polymers (such as pectin (PEC)) that could form the most extensive hydrogen bonding and/or ionic interactions with $\mathrm{TClHCl}$ were the most effective crystallization inhibitors, extending the physical stability of $\mathrm{TClHCl}$ in the amorphous state better than polymers (such as polyvinylpyrrolidone (PVP)) with fewer intermolecular interactions with the vitamin form [8]. Amorphous forms of ingredients tend to be more chemically labile than their crystalline counterparts [9], which was found to be true for the thiamine in the $\mathrm{TClHCl}$ solid dispersions; however, differences in the chemical stability of thiamine in the amorphous state in the presence of different polymers were also found [10]. In the amorphous $\mathrm{TClHCl}$ solid dispersions, thiamine was more chemically stable in the presence of pectin compared to PVP, which can be attributed to the increased intermolecular interactions between pectin and thiamine and the more acidic nature of pectin [10].

The interesting insights into the physical and chemical stability of thiamine in amorphous TClHCl solid dispersions developed in previous work $[8,10]$ are extended here to the ingredient form of thiamine (TMN) that is more often used in low and intermediate moisture foods and dietary supplements, wherein crystallization and degradation in different solid states are highly relevant. Although TMN is potentially found in its amorphous form in food and dietary supplement products, there has been no study conducted to investigate its physical and chemical stability in the amorphous form. It was anticipated that co-formulation of TMN with polymers would result in successful amorphization of the vitamin due to its interactions with polymeric ingredients, similar to what was found in the TClHCl:polymer dispersions [8]. The effects of counterion and $\mathrm{pH}$ differences on the stability of thiamine in the $\mathrm{TClHCl}$ versus TMN solid dispersions were of interest. Therefore, the objectives of this study were: (1) to investigate physical and chemical stability of amorphous TMN in solid dispersions made using PVP and pectin (which were selected based on their $\mathrm{T}_{\mathrm{g}}$, hydrogen bonding ability, molecular structures, and hygroscopicity); (2) to compare thiamine degradation in the amorphous and crystalline state; (3) to determine the factors causing chemical instability of thiamine in amorphous form; and (4) to compare thiamine stability in polymer dispersions containing TMN to previous reports of those containing $\mathrm{TClHCl}[8,10]$.

\section{Results and Discussion}

\subsection{Physical Stability of Amorphous Thiamine Mononitrate}

TMN was successfully amorphized in the presence of both PVP and PEC (Figure 1). To form fully amorphous dispersions, at least $90 \%$ PVP or $80 \%$ PEC was necessary to initially stabilize TMN in the amorphous state in the solid dispersions (Figure 2). A higher ratio of polymer was needed to amorphize TMN compared to TClHCl. Only $60 \%$ PVP or $40 \%$ PEC was required to fully amorphize TClHCl [8], indicating that TMN may have a higher crystallization tendency than TClHCl. For both thiamine salt forms, more PVP was needed to form amorphous dispersions of the vitamin than PEC, indicating that different traits between the polymers, in addition to the salt form of thiamine, influenced the formation of amorphous solid dispersions.

No evidence of TMN crystallization was found in PXRD patterns of TMN:polymer dispersions that were initially amorphous (TMN:PVP containing $\leq 10 \% \mathrm{TMN}$ and TMN:PEC containing $\leq 20 \%$ $\mathrm{TMN}$ ) in samples stored at $11 \% \mathrm{RH}$ over the 8 week storage study, regardless of storage temperature. PXRD patterns of amorphous 5TMN:95polymer dispersions before and after storage are shown in 
Figure 2. Increasing the storage RH to 75\% RH did not lead to TMN crystallization in the 5TMN:95PEC dispersions (Figure 2B).

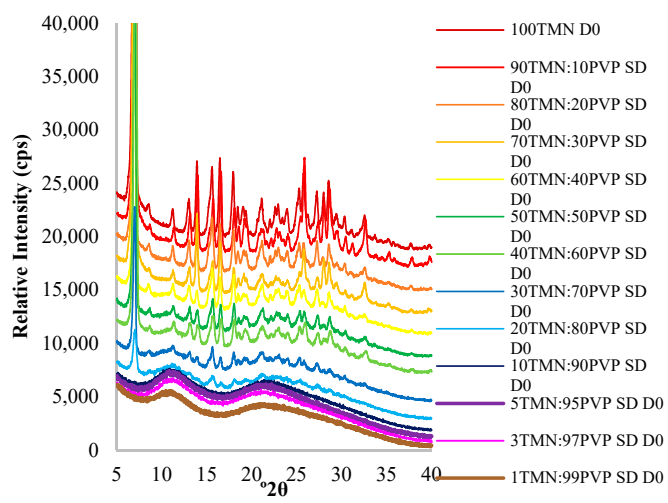

(A)

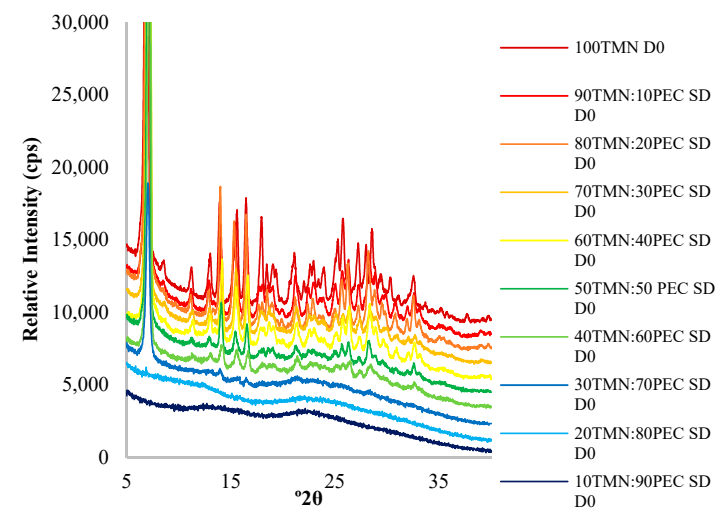

(B)

Figure 1. X-ray powder diffraction patterns of (A) TMN:PVP solid dispersions (SD) prepared with varying ratios of thiamine mononitrate (TMN) to polyvinylpyrrolidone (PVP) immediately following lyophilization; and (B) thiamine mononitrate:pectin (TMN:PEC) solid dispersions (SD) prepared with varying ratios of TMN to PEC immediately following lyophilization. The diffractograms are presented from top to bottom in decreasing order of TMN concentration.

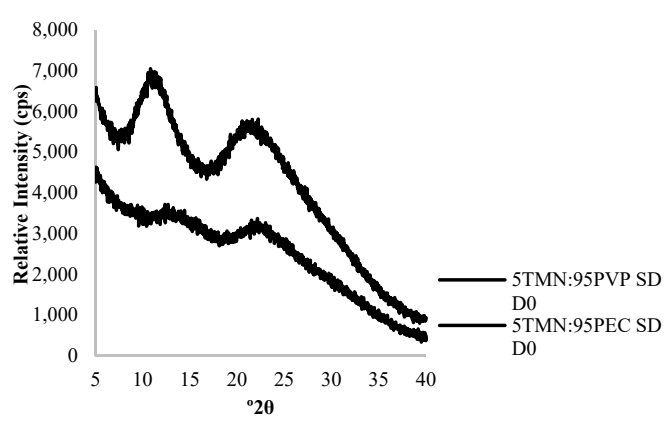

(A)

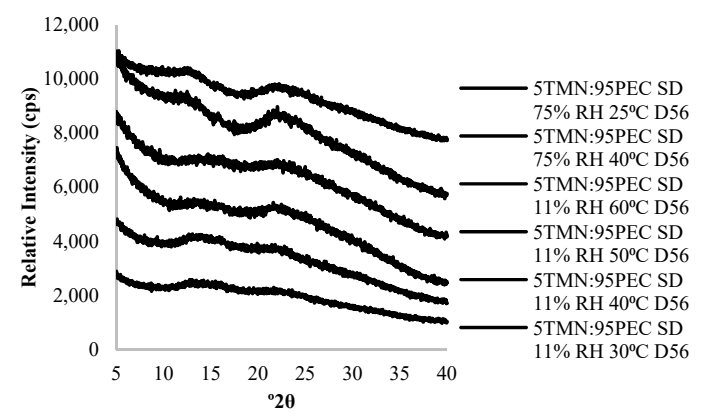

(B)

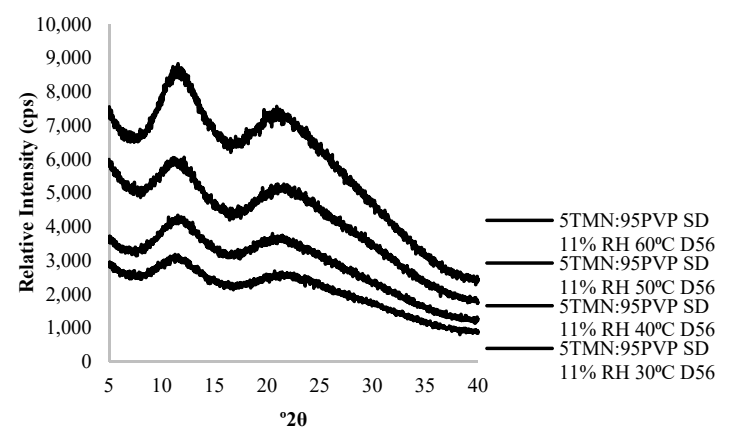

(C)

Figure 2. X-ray powder diffraction patterns of: (A) 5TMN:95PEC and 5TMN:95PVP solid dispersions (SD) immediately following lyophilization; (B) 5TMN:95PEC solid dispersions (SD) stored at $11 \%$ relative humidity (RH), $30-60{ }^{\circ} \mathrm{C}$ and $75 \% \mathrm{RH}, 25$ or $40{ }^{\circ} \mathrm{C}$ on day 56 ; and (C) 5TMN:95PVP solid dispersions (SD) stored at $11 \% \mathrm{RH}$ and $30-60{ }^{\circ} \mathrm{C}$ on day 56.

At the 75\% RH storage conditions, the 5TMN:95PVP dispersions liquefied, and thus no PXRD patterns were collected. In comparison, $\mathrm{TClHCl}$ :polymer dispersions that were initially amorphous 
remained so during storage at low $\mathrm{RHs}$ (e.g., $\leq 32 \% \mathrm{RH}$ for $50 \mathrm{TClHCl}: 50 \mathrm{PEC}$ dispersions), but increasing the storage $\mathrm{RH}$ resulted in $\mathrm{TClHCl}$ crystallization in many of the polymer dispersions [8].

\subsection{Effect of Polymer Type on Amorphization and Physical Stability of TMN Dispersions}

Hydrogen bonding between a low molecular weight compound and a polymer has often been cited as an important stabilizing factor for both amorphization of the small molecule and physical stability of the amorphous solid dispersions against recrystallization, in which hydrogen bonding propensity is dependent on hydrogen bond donor (HBD) and acceptor (HBA) groups on the two materials [8,11-15]. In FTIR spectra, peak shifts to lower wavenumbers in spectra of vitamin:polymer dispersions compared to spectra of pure polymers indicate more extensive and/or stronger intermolecular interactions. Additionally, the presence or absence of distinct peaks in the $\mathrm{OH} / \mathrm{NH}$ stretching region $\left(3600-3000 \mathrm{~cm}^{-1}\right)$ of TClHCl:polymer spectra corresponded to the PXRD data such that the FTIR spectra were also indicative of presence/absence of the crystalline salt form of thiamine in the dispersion [8]. In our previous study of amorphous $\mathrm{TClHCl}$ polymer dispersions, FTIR spectra indicated substantial hydrogen bonding between $\mathrm{TClHCl}$ and PEC, attributed to the HBAs on thiamine and HBDs on PEC, but there was little-to-no hydrogen bonding observed between $\mathrm{TClHCl}$ and PVP, attributed to the lack of HBDs on PVP [8]. This difference in hydrogen bonding corresponded to differences in physical stability: more PVP was needed to inhibit TMN crystallization than PEC [8].

A similar analytical approach was used for the TMN:polymer dispersions. Spectra of crystalline TMN exhibited three distinct peaks in the $\mathrm{OH} / \mathrm{NH}$ spectral region, located at 3329, 3141 and $3047 \mathrm{~cm}^{-1}$ (Figure $3 \mathrm{~A}$ ), and several other peaks were found in the double bond region of the TMN spectra (1800-1500 $\mathrm{cm}^{-1}$ ) (Figure 3B). In TMN:PEC dispersions in which TMN remained crystalline according to PXRD analyses (those containing $<80 \%$ PEC), the distinct crystalline TMN peaks in both the $\mathrm{OH} / \mathrm{NH}$ and double bond regions remained in the FTIR spectra (Figure 3A,B). Upon successful amorphization of TMN in the polymer dispersions according to PXRD analyses (in TMN:PEC dispersions containing $\geq 80 \%$ PEC), these distinct peaks disappeared, and instead broad peaks were formed in both regions of the FTIR spectra. Thus, as for the TClHCl:polymer dispersions [8], PXRD and FTIR analyses identified the same TMN:polymer ratios needed to prevent TMN crystallization in the initial TMN:polymer lyophiles.

Differences were found in peak shifts in FTIR spectra of varying ratios and types of polymers in the TMN:polymer dispersions between the polymer types. The maximum peak in the hydroxyl region of spectra of pure PEC polymer occurred at $3419 \mathrm{~cm}^{-1}$, and this peak shifted to $3363 \mathrm{~cm}^{-1}$ in the spectra of amorphous dispersions containing 20TMN:80PEC (Figure 3A). A smaller peak shift was found in the double bond region, from $1622 \mathrm{~cm}^{-1}$ in the spectra of PEC alone to 1606 and $1610 \mathrm{~cm}^{-1}$ in the amorphous 20TMN:80PEC and 5TMN:95PEC dispersions, respectively (Figure 3B). The large peak shift in the hydroxyl region of the spectra indicates hydrogen bonding occurred between TMN and PEC in amorphous dispersions. Unlike PEC, however, the only functional group of PVP that can participate in hydrogen bonding is the amide carbonyl group (HBA), which absorbs at $1669 \mathrm{~cm}^{-1}$ in the double bond region of the FTIR spectra (Figure 3C). However, in amorphous solid dispersions with TMN, this peak either shifted to a higher wavenumber, indicating greater interaction between PVP molecules (less interaction between TMN and PVP), or remained in the same location, indicating that there were limited-to-no hydrogen bonding and/or intermolecular interactions between PVP and TMN, similar to what was seen in spectra of TClHCl:PVP dispersions [8]. The relatively stronger and/or more extensive hydrogen bonding/intermolecular interactions between TMN and PEC compared to TMN and PVP was likely the reason that less PEC was required to amorphize TMN than PVP.

Comparing the peak shifts in spectra of TMN:PEC dispersions to those previously reported for TClHCl:PEC dispersions [8] provides evidence as to why more PEC was needed to amorphize TMN than $\mathrm{TClHCl}$. A larger peak shift $\left(148 \mathrm{~cm}^{-1}\right)$ was found in the $\mathrm{OH} / \mathrm{NH}$ spectral region of the TClHCl:PEC dispersions than the $56 \mathrm{~cm}^{-1}$ shift in the same spectral region of the TMN:PEC dispersions, indicating that there were more extensive and/or stronger intermolecular hydrogen bonding interactions between the $\mathrm{TClHCl}$ and PEC than between the TMN and PEC. The fact that there is an additional hydrogen 
bond donor in the structure of $\mathrm{TClHCl}$ compared to $\mathrm{TMN}$ was likely the contributing factor to this difference. Because TMN had one less hydrogen bond donor than $\mathrm{TClHCl}$, more polymer was needed to stabilize the TMN in the amorphous state than $\mathrm{TClHCl}$.

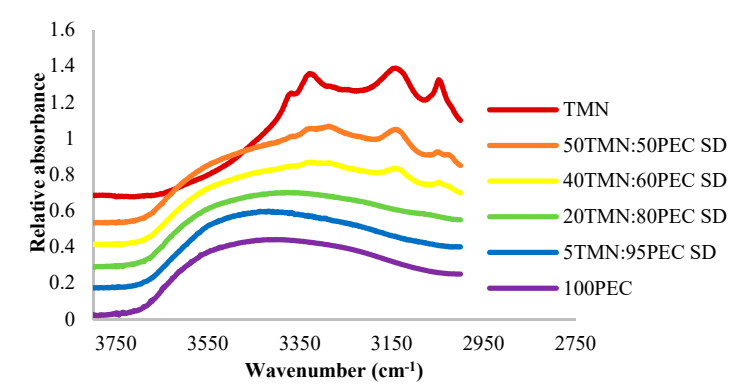

(A)

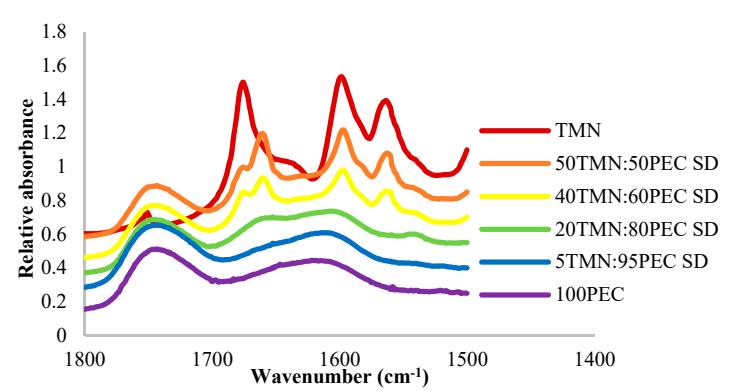

(B)

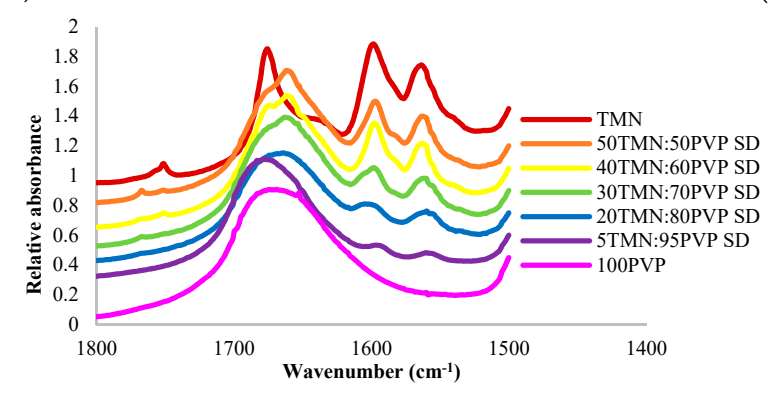

(C)

Figure 3. FTIR spectra of the (A) hydroxyl region of TMN:PEC solid dispersions, (B) carbonyl region of TMN:PEC solid dispersions, and (C) carbonyl region of TMN:PVP solid dispersions. The spectra are presented from top to bottom in decreasing order of TMN concentration.

\subsection{Effect of Physical State on Chemical Stability of Thiamine}

The physical state (amorphous vs. crystalline) of a compound is known to influence its chemical stability. Amorphous materials, including thiamine, are generally less chemically stable than their crystalline counterparts $[10,16]$. In the current study, the chemical stability of thiamine in the crystalline state was measured over an 8-week period of storage in different environments (at $11 \% \mathrm{RH}$ and $30-60^{\circ} \mathrm{C}$ and $75 \% \mathrm{RH}$ and $25-40{ }^{\circ} \mathrm{C}$ ) in three sample types: (1) pure crystalline TMN (control); (2) physical mixtures containing 5\% crystalline TMN and 95\% PEC; and (3) physical mixtures containing 5\% crystalline TMN and 95\% PVP. Regardless of the storage RH and temperature, no significant $(p<0.05)$ thiamine degradation was found in the neat crystalline TMN control samples over the 8 weeks (Figure 4A). Similarly, there was no significant $(p<0.05)$ thiamine degradation in TMN physical blends with PEC or PVP throughout the study, with one exception (Figure 4B). In TMN:PVP physical blends stored at $75 \% \mathrm{RH}$ and $40{ }^{\circ} \mathrm{C}$, more than $70 \%$ thiamine loss was found over the 8 -week period. This was presumably due to the hygroscopic nature of PVP, especially at 75\% RH. Moisture sorption studies indicated that moisture sorption of both the TMN:polymer dispersions and the physical mixtures was governed by the hygroscopicity of the polymers rather than TMN at these ingredient ratios and storage conditions. Neat PVP absorbed 15\% more moisture than PEC at 75\% RH (33\% and $18 \% \mathrm{w} / \mathrm{w}$ in PVP and PEC, respectively) (Figure 5A), and this increased amount of moisture sorption by PVP in the physical blends led to at least partial dissolution of the crystalline TMN. Since thiamine is less stable in solution than in the solid state [5], the partial dissolution of crystalline TMN in the physical mixture led to extensive degradation at this high RH storage condition. However, TMN that remained crystalline was shown to be chemically stable in the current study, with no significant degradation after 8 weeks in any storage condition (Figure 4). Differences in hygroscopicity of the polymers led 
to similar differences in hygroscopicity of the solid dispersions, wherein dispersions containing PVP absorbed more water than those containing PEC: the 5TMN:95PVP dispersions absorbed 12\% more moisture than the 5:TMN:95PEC dispersions at 75\% RH (32\% and 20\% w/w in 5TMN:95PVP and 5:TMN:95PEC, respectively) (Figure 5B). The increased moisture sorption by the dispersions containing PVP led to their hydration when stored at 75\% RH, consistent with the dissolution of crystalline TMN in a physical mixture with PVP stored at the same conditions.

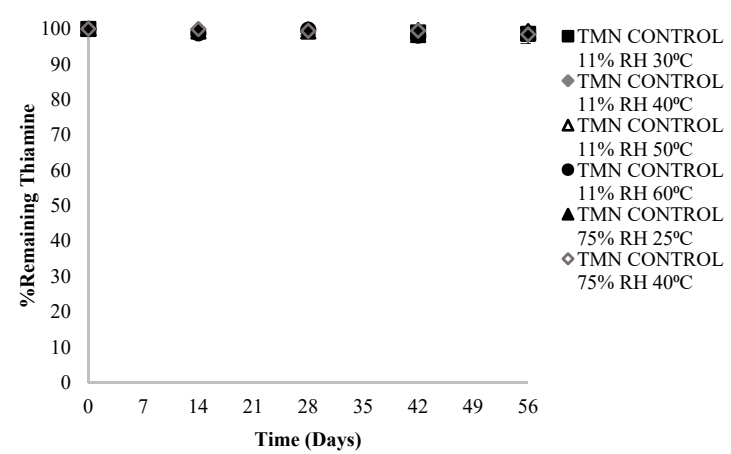

(A)

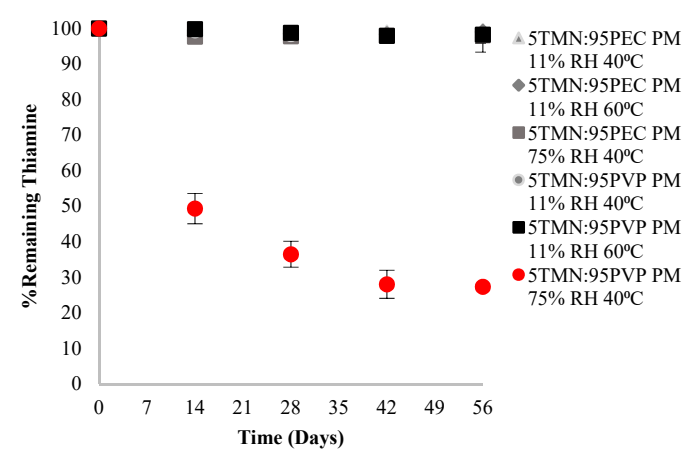

(B)

Figure 4. Chemical stability of thiamine (A) in pure crystalline TMN form, and (B) in 5TMN:95PEC and 5TMN:95PVP physical mixtures (PM).

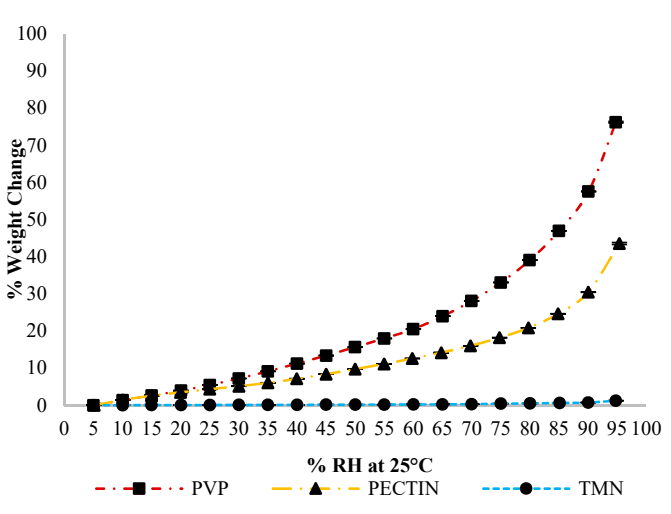

(A)

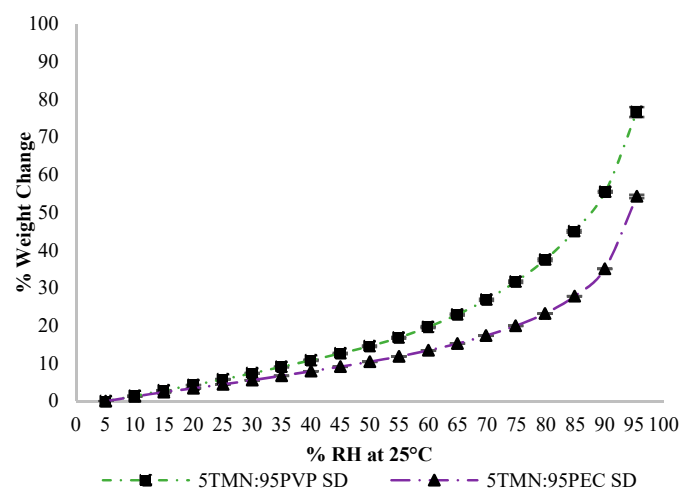

(B)

Figure 5. Moisture sorption profiles of (A) pure PVP, PEC, and TMN; and (B) solid dispersions of 5TMN:95PVP and 5TMN:95PEC following lyophilization at $25^{\circ} \mathrm{C}$.

Thiamine degradation was also monitored in amorphous solid dispersions: in 5TMN:95PEC and 5TMN:95PVP solid dispersions at 11\% RH and four different temperatures $\left(30,40,50\right.$ and $\left.60{ }^{\circ} \mathrm{C}\right)$, storage conditions in which no evidence of TMN crystallization was found for the duration of the study (Figure 2). Up to $5 \%$ thiamine degradation occurred in the amorphous 5TMN:95PEC dispersions stored at $11 \%$ RH over the course of the 8-week storage study, with no significant differences in thiamine degradation found between storage temperatures (Figure 6A). Despite no significant difference in moisture sorption (amounting to $<2 \% \mathrm{w} / \mathrm{w}$ ) at these $11 \% \mathrm{RH}$ storage conditions (as shown in Figure 5B), more thiamine degraded in the amorphous 5TMN:95PVP dispersions, with thiamine degradation increasing as temperature increased and $\mathrm{RH}$ was maintained at $11 \% \mathrm{RH}$ (Figure 6B). Nearly $14 \%$ of thiamine degraded in the 5TMN:95PVP dispersions stored at $11 \% \mathrm{RH}$ and $50{ }^{\circ} \mathrm{C}$ over the duration of the study, and 23\% of thiamine degraded in the 5TMN:95PVP amorphous dispersions stored at $60{ }^{\circ} \mathrm{C}$ (Figure 6B). Thus, polymer type had a notable influence on the chemical stability of thiamine in the amorphous solid dispersions independent of moisture sorption, with the PEC polymer better stabilizing amorphous thiamine to chemical degradation than PVP at the $11 \%$ RH storage conditions. 


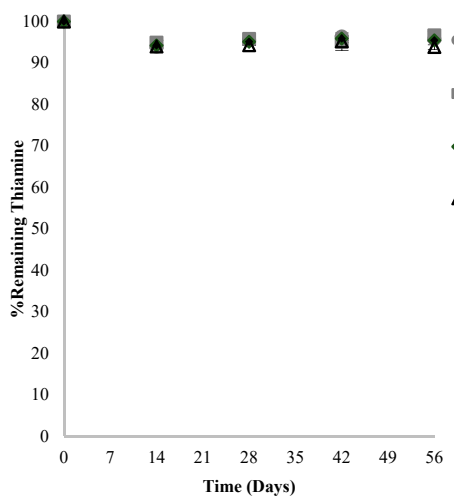

(A)

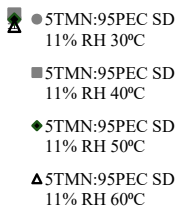

$\triangle 5$ TMN:95PEC SD

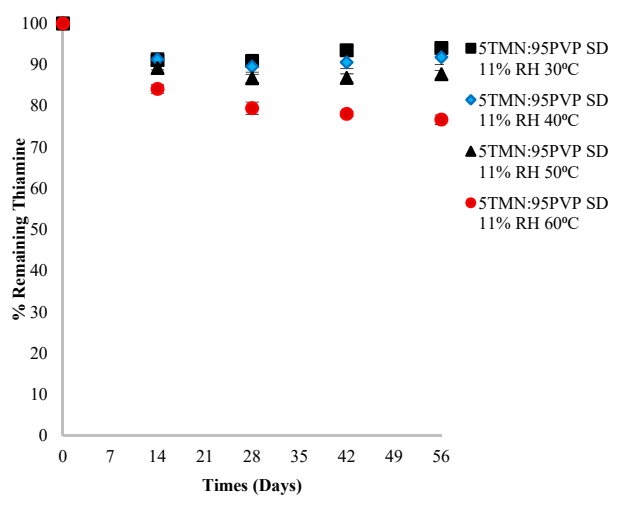

(B)

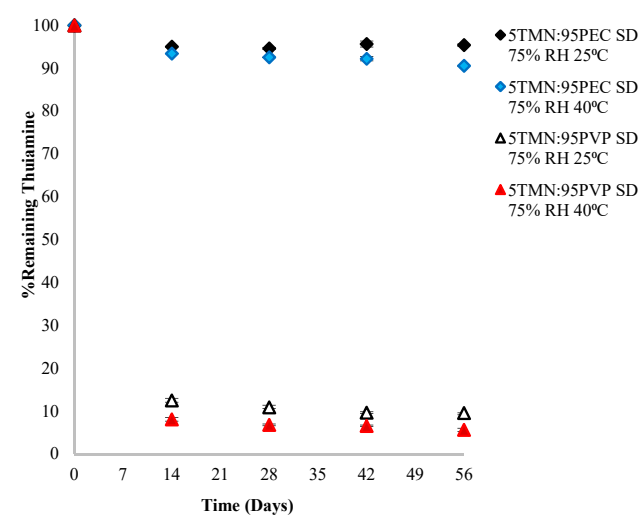

(C)

Figure 6. Chemical stability of thiamine (A) in 5TMN:95PEC solid dispersions (SD), (B) in 5TMN:95PVP dispersions (SD) stored at $11 \% \mathrm{RH}$ and $30-60{ }^{\circ} \mathrm{C}$ for 56 days, and (C) in 5TMN:95PEC solid dispersions (SD) and 5TMN:95PVP dispersions stored at $75 \% \mathrm{RH}$ and 25 or $40{ }^{\circ} \mathrm{C}$ for 56 days.

Increasing the storage $\mathrm{RH}$ to $75 \% \mathrm{RH}$ resulted in drastic differences in thiamine degradation between the 5TMN:95PEC and 5TMN:95PVP amorphous dispersions (Figure 6C), with thiamine being significantly $(p<0.05)$ more stable in the dispersions made with PEC. In the $75 \% \mathrm{RH}$ environment, $\sim 5 \%$ and $\sim 9 \%$ of thiamine had degraded in the TMN:PEC dispersions stored at $25{ }^{\circ} \mathrm{C}$ and $40{ }^{\circ} \mathrm{C}$, respectively, over the 8-week duration of the study. In contrast, after only 2 weeks of storage at $75 \% \mathrm{RH}$, $87 \%$ and $92 \%$ of thiamine had degraded, at 25 and $40{ }^{\circ} \mathrm{C}$ respectively, in the 5TMN:95PVP dispersions. After this 2-week period, thiamine continued to slowly degrade in these TMN:PVP dispersions, and only $\sim 10 \%$ and $\sim 6 \%$ of thiamine remained at the end of the 8-week study following storage at $75 \% \mathrm{RH}$ and 25 or $40{ }^{\circ} \mathrm{C}$, respectively (Figure $6 \mathrm{C}$ ). The dramatic increase in thiamine degradation in the 5TMN:95PVP dispersions stored at the higher RH was attributed to the solubilization of TMN in the 95\% PVP dispersions due to the hygroscopicity of PVP (Figure 5), similarly to the increased degradation of dissolved crystalline TMN in the physical mixtures with PVP stored at this higher RH (Figure 4B). However, even in the samples stored at $11 \%$ RH, where water content was much lower and not a differentiating factor, amorphous TMN was more chemically stable in the presence of PEC than PVP. This was presumably due to stronger/more extensive intermolecular interactions between TMN and PEC than between TMN and PVP (Figure 3), consistent with previous studies on the effect of intermolecular interactions on chemical stability of components within amorphous solid dispersions $[10,17]$. In general, thiamine was less chemically stable in the amorphous state than in the crystalline state, and the chemical stability of thiamine in amorphous solid dispersions was dependent on polymer type due to both intermolecular interactions with the polymer and the 
variable hygroscopicity of the systems in the different storage environments. To further explore the differences in chemical stability within the amorphous solid dispersions, a series of additional studies were completed.

\subsection{Effect of Glass Transition Temperature on Thiamine Stability}

Chemical stability of amorphous materials, including thiamine, is often related to $\mathrm{T}_{\mathrm{g}}$ : samples with lower $\mathrm{T}_{\mathrm{g}}$ values often have lower chemical stabilities (enhanced reactivities) due to increased molecular mobility especially above the $T_{g}[9,18,19]$. Although the $T_{g}$ of pure amorphous $T M N$ could not be measured due to its inability to amorphize in the absence of a polymer, using the Boyer-Beaman rule, $\left(\mathrm{T}_{\mathrm{g}}=2 / 3 * \mathrm{~T}_{\mathrm{m}}\right)$ [20], the $\mathrm{T}_{\mathrm{g}}$ of TMN was estimated as $\sim 40{ }^{\circ} \mathrm{C}$. The $\mathrm{T}_{\mathrm{g}}$ values of PVP and PEC are reported to be 134 and $90^{\circ} \mathrm{C}$, respectively [8], indicating that PVP-containing lyophiles should have higher $\mathrm{T}_{\mathrm{g}}$ values than PEC-containing lyophiles, all other factors remaining constant. Applying the Fox and Gordon-Taylor equations, which are used to predict the $\mathrm{T}_{\mathrm{g}}$ values of systems containing more than one component as a function of weight fractions of the components [21,22], it can be assumed that as the proportion of polymer increased in the amorphous TMN:polymer dispersions, their $\mathrm{T}_{\mathrm{g}}$ values also increased, due to the higher $\mathrm{T}_{\mathrm{g}}$ values of the polymers compared to TMN. Accordingly, immediately following lyophilization, the $\mathrm{T}_{\mathrm{g}}$ values of 5TMN:95PVP and 10TMN:90PVP dispersions were 65 and $60^{\circ} \mathrm{C}$, respectively (Table 1). Following storage of the 5TMN:95PVP dispersions at $11 \% \mathrm{RH}$ and either 30 or $60^{\circ} \mathrm{C}$, their $\mathrm{T}_{\mathrm{g}}$ values were measured as 49 and $52{ }^{\circ} \mathrm{C}$, respectively (Table 1). Increasing the moisture contents of samples, such as by exposing them to humidity in the environment, decreases their $\mathrm{T}_{\mathrm{g}}$ values (refer to the Fox and Gordon-Taylor equations: water has a $\mathrm{T}_{\mathrm{g}}$ of $\left.-137^{\circ} \mathrm{C}[19,21,22]\right)$. Storing the dry lyophiles of $5 \mathrm{TMN}: 95 \mathrm{PVP}$ at $11 \% \mathrm{RH}$ resulted in enough moisture sorption to decrease the $\mathrm{T}_{\mathrm{g}}$ from the initial $65{ }^{\circ} \mathrm{C}$ to $49-52{ }^{\circ} \mathrm{C}$. The TMN:PVP dispersions stored at $11 \% \mathrm{RH}$ and $60{ }^{\circ} \mathrm{C}$ had absorbed enough water to depress their $\mathrm{T}_{\mathrm{g}}$ values below the storage temperature, indicating that these dispersions were in the supercooled liquid state in this $60^{\circ} \mathrm{C}$ storage condition. This change in state from the glassy amorphous state at lower temperatures to the supercooled liquid state at $60{ }^{\circ} \mathrm{C}$ corresponded to a significant increase in thiamine degradation in 5TMN:95PVP dispersions after 56 days of storage at $60{ }^{\circ} \mathrm{C}(24 \%$ thiamine degradation), compared to that in 5TMN:95PVP dispersions stored at lower temperatures ( $<14 \%$ thiamine degradation) (Figure $6 \mathrm{~B}$ ). These results are consistent with the concept that amorphous materials are more stable in the glassy state than in the supercooled liquid state due to differences in molecular mobility [18]. The $\mathrm{T}_{\mathrm{g}} \mathrm{s}$ of the PEC-containing lyophiles were difficult to identify in the DSC scans, attributed to the polydispersity of the PEC.

Table 1. Onset glass transition temperatures of TMN:PVP solid dispersions after lyophilization and equilibration at $11 \% \mathrm{RH}$ and 30 or $60^{\circ} \mathrm{C}$. Superscript letters denote statistical significance.

\begin{tabular}{ccc}
\hline Sample & Storage Condition & Onset $\mathbf{T}_{\mathbf{g}}\left({ }^{\circ} \mathbf{C}\right)$ \\
\hline 5TMN:95PVP & 'As is' following lyophilization & $65 \pm 7^{\mathrm{B}}$ \\
5TMN:95PVP & $11 \% \mathrm{RH}$ and $30^{\circ} \mathrm{C}$ & $49 \pm 1^{\mathrm{A}}$ \\
5TMN:95PVP & $11 \% \mathrm{RH}$ and $60^{\circ} \mathrm{C}$ & $52 \pm 3^{\mathrm{A}}$ \\
10TMN:90PVP & 'As is' following lyophilization & $60 \pm 4^{\mathrm{B}}$ \\
\hline
\end{tabular}

Interestingly, thiamine was more chemically stable in the 10TMN:90PVP dispersions than in the 5TMN:95PVP dispersions (Figure 7) at storage temperatures below the $\mathrm{T}_{\mathrm{g}}$, despite the lower $\mathrm{T}_{\mathrm{g}}$ of the 10TMN:90PVP dispersion, indicating that factors beyond $\mathrm{T}_{\mathrm{g}}$ are likely contributing to the stability differences of the vitamin in different amorphous dispersions especially in the glassy state. A number of studies have shown that $\mathrm{T}_{\mathrm{g}}$ does not always correlate to chemical stability $[10,23-26]$. For example, aspartame chemical stability in the presence of PVP did not change even when $\mathrm{T}_{\mathrm{g}}$ was increased [23], ascorbic acid exhibited degradation even in the glassy state [24], and thiamine degraded more in amorphous $\mathrm{TClHCl}$ :polymer dispersions with the highest $\mathrm{T}_{g}$ values than in these dispersions with lower $T_{g}$ values [10]. Thus, although there was some correlation of $T_{g}$ and chemical stability within the same formulation (5TMN:95PVP) in the current study, with the most degradation observed in the 
amorphous dispersion stored at a temperature above its $T_{g}$, the $T_{g}$ was not the only factor accounting for differences in chemical stability across different polymer (PVP vs. PEC) or vitamin:polymer ratio formulations.

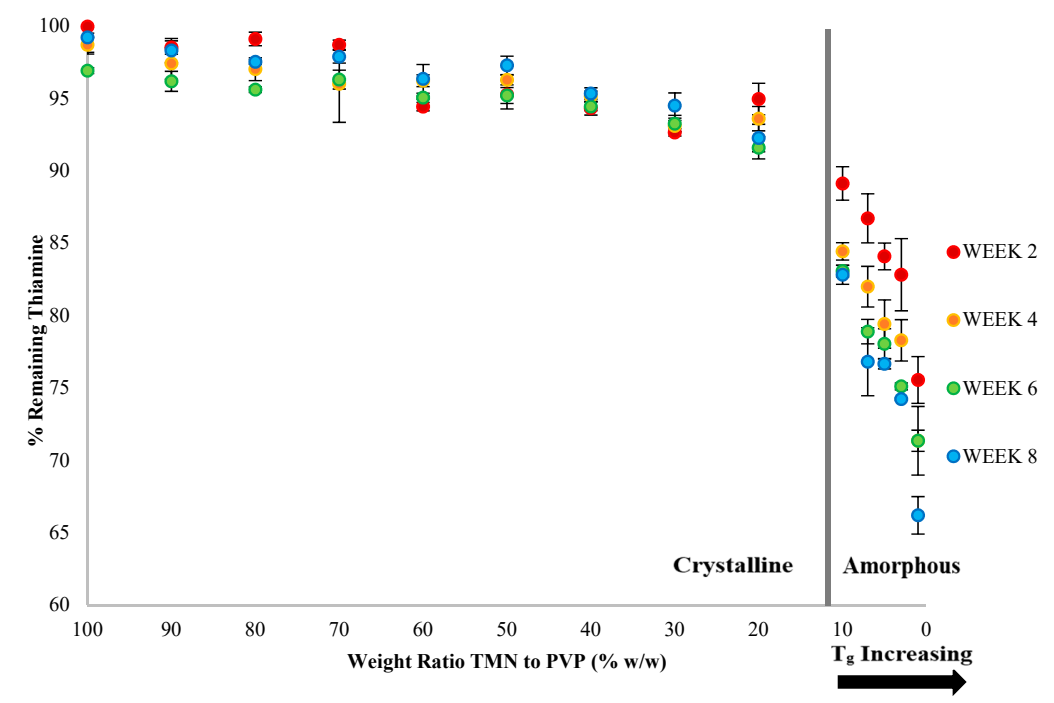

Figure 7. Chemical stability of thiamine in various ratios of TMN to PVP solid dispersions stored at $11 \% \mathrm{RH}$ and $60^{\circ} \mathrm{C}$ for 56 days.

\subsection{Effect of Vitamin:Polymer Ratio in Solid Dispersions on Thiamine Stability}

The chemical stability of amorphous thiamine has also been shown to relate to the polymer proportion in TClHCl:PVP solid dispersions [10]. To explore this possibility with TMN, PVP dispersions composed of increasing ratios of TMN (1-100\%) were lyophilized and stored at $11 \% \mathrm{RH}$ and $60^{\circ} \mathrm{C}$ for 56 days. The samples were analyzed for physical state over the duration of the experiment, and at least $90 \%$ PVP was needed to amorphize TMN (Figure 2A). These initially amorphous TMN dispersions containing $\geq 90 \%$ PVP remained amorphous for the duration of the study at this storage condition. The percent thiamine remaining in these dispersions throughout the storage study was also documented to correlate the physical state of the vitamin with its chemical reactivity. The PVP dispersions containing $\leq 10 \%$ TMN remained amorphous and thus enabled documentation of thiamine stability in the amorphous state, whereas TMN crystallized in the PVP dispersions containing $>10 \% \mathrm{TMN}$ and thus the stability of thiamine in these dispersions would have been influenced by the crystalline state of the vitamin in the presence of PVP.

Significant $(p<0.05)$ differences in thiamine stability were found between the TMN:PVP dispersions in which TMN had crystallized and those that remained amorphous (Figure 7), with thiamine degrading significantly $(p<0.05)$ more in the amorphous systems. Of the TMN:PVP systems in which TMN had crystallized, significantly $(p<0.05)$ more thiamine had degraded in the 20TMN:80PVP dispersions by the end of the experiment (day 56, $8 \%$ degradation) than in the dispersions containing higher proportions of TMN. A similar observation was found in a previous study, in which only partial crystallization (some amorphous thiamine still present) led to some degradation in a crystallized dispersion [10].

Interestingly, more thiamine degradation was found in the physical mixtures of $5 \%$ crystalline TMN with 95\% PVP at $60{ }^{\circ} \mathrm{C}$ and $11 \%$ RH (Figure 6B) than in the 5TMN:95PVPdispersions that had been co-lyophilized (in which the TMN had recrystallized) and stored in the same conditions (Figure 7), indicating that the sample preparation and resulting matrix also influenced vitamin stability. However, in the TMN:PVP dispersions prepared by lyophilization, a marked difference was found in the chemical stability of thiamine between systems that remained amorphous and those in which TMN had crystallized. In the TMN:PVP dispersions that remained amorphous (Figure 7), as the proportion of PVP in the dispersion increased, the thiamine stability decreased, consistent with some previous studies on chemical stability of vitamins (thiamine from $\mathrm{TClHCl}$ and ascorbic acid) as a function of proportion 
of PVP in amorphous dispersions [10,24]. Over the 8-week study, 23\%, 23\%, and 26\% of thiamine degraded in the TMN:PVP dispersions containing 7\%, 5\%, and 3\% TMN, respectively (Figure 7). The most thiamine degradation (34\%) was found in the amorphous TMN:PVP dispersions containing only 1\% TMN (Figure 7). This finding is important because thiamine fortification or enrichment levels in foods are low, and thiamine appears to be most reactive (and least stable) at low proportions in amorphous systems.

To further explore differences in thiamine stability in amorphous solid dispersions with increasing ratios of PVP, reaction kinetics of thiamine degradation were calculated. Thiamine is known to degrade in a first-order or pseudo-first order reaction $[7,27]$. Reaction rate constants $\left(\mathrm{k}_{\mathrm{obs}}\right)$ were calculated for the samples with different TMN and PVP ratios up to 20\% TMN (higher TMN proportions did not degrade enough in the timeframe of the current study for accurate calculations). The $\mathrm{k}_{\mathrm{obs}}$ values increased from 0.0038 to $0.0055 \mathrm{day}^{-1}$ as PVP proportion increased from $90 \%$ to $99 \%$ (Table 2). However, as the PVP ratio decreased to $80 \%$, in which TMN had at least partially crystallized, the $\mathrm{k}_{\mathrm{obs}}$ value was only $0.0018 \mathrm{day}^{-1}$. The $\mathrm{t}_{90}$ value (time where $90 \%$ of the initial concentration of thiamine remained) in this 20TMN:80PVP was 58.5 days, whereas the $t_{90}$ values of dispersions in which TMN remained in the amorphous state were all less than 28 days (Table 2), indicating the relatively higher stability of the crystallized TMN compared to the amorphous samples.

Table 2. Reaction rate constants and $\mathrm{t}_{90}$ values for thiamine degradation in $\mathrm{TMN}$ and $\mathrm{TClHCl}$ solid dispersions prepared with different proportions of PVP when stored at $11 \% \mathrm{RH}$ and $60^{\circ} \mathrm{C}$.

\begin{tabular}{|c|c|c|c|c|}
\hline Thiamine Salt Form & \% PVP & $k_{\text {obs }}\left(\right.$ day $\left.^{-1}\right)$ & $\mathbf{R}^{2}$ & t $_{90} *$ (days $)$ \\
\hline \multirow{6}{*}{ TMN } & 99 & 0.0055 & 0.7981 & 19.2 \\
\hline & 97 & 0.0054 & 0.9217 & 19.5 \\
\hline & 95 & 0.0050 & 0.8637 & 21.1 \\
\hline & 93 & 0.0049 & 0.9371 & 21.5 \\
\hline & 90 & 0.0038 & 0.9155 & 27.7 \\
\hline & 80 & 0.0018 & 0.9464 & 58.5 \\
\hline \multirow{6}{*}{$\mathrm{TClHCl}^{1}$} & 99 & 0.0062 & 0.96 & 17 \\
\hline & 97 & 0.0047 & 0.95 & 22 \\
\hline & 95 & 0.0038 & 0.95 & 28 \\
\hline & 93 & 0.0032 & 0.93 & 33 \\
\hline & 90 & 0.0025 & 0.95 & 42 \\
\hline & 80 & 0.0015 & 0.92 & 70 \\
\hline
\end{tabular}

${ }^{1}$ Arioglu-Tuncil, Voelker, Taylor and Mauer [10]. ${ }^{*} t_{90}$ : Time when $90 \%$ of the initial concentration of thiamine remained.

It is important to note that the $\mathrm{t}_{90}$ value decreased as PVP proportion increased in the amorphous dispersions (i.e., 28 days and 19 days in 90\% and 99\% PVP dispersions, respectively) (Table 2). Since the observation that increasing amounts of PVP led to increased thiamine degradation could not be attributed to $T_{g}$, this was instead explained by a kinetic model proposed by Waterman, et al. [28]. This model proposes that the degradation rate of a drug is affected by the drug to excipient ratio only if the excipient is in excess, wherein a greater surface area of contact between the drug and excipient leads to greater drug degradation [28]. This mechanism has been shown previously to occur in the case of thiamine in TClHCl:PVP dispersions [10] and is also presumably occurring in the current study. As the number of PVP molecules increased relative to TMN, thiamine-polymer interactions increased, leading to a decrease in thiamine-thiamine interactions. The thiamine-polymer interactions were destructive to the chemical stability of thiamine and led to the increased rate of thiamine degradation (Table 2). Thus, thiamine stability was dictated more by molecular interactions between TMN and polymer than by $\mathrm{T}_{\mathrm{g}}$ in the glassy state.

\subsection{Comparison of Thiamine Stability in TMN and TClHCl Solid Dispersions}

\subsubsection{Physical Stability}

$\mathrm{TMN}$ and $\mathrm{TClHCl}$ are both used commercially in the food and pharmaceutical industries; therefore, comparing the physical and chemical stability of these two salt forms of thiamine in the amorphous 
state is advantageous for many food and pharmaceutical products. When using PEC and PVP to amorphize thiamine, $\mathrm{TMN}$ required more polymer than $\mathrm{TClHCl}$ for amorphization regardless of the polymer type used: $\mathrm{TClHCl}$ was successfully amorphized with a minimum of $40 \%$ and $60 \%$ of PEC and PVP, respectively [8], while at least $80 \%$ PEC and 90\% PVP were required to amorphize TMN (Figure 1). Polymers contribute to the amorphization of crystalline materials during lyophilization by disrupting thiamine-thiamine interactions in the crystal lattice structure and instead forming thiamine-polymer interactions. However, the nature of the counterion present in the crystal lattice (i.e., nitrate in TMN vs. chloride in $\mathrm{TClHCl}$ ) plays a role in the strength of interactions and packing of the crystal lattice [29]; thus the differences in amorphization tendency, physical stability, and other physicochemical properties (Table 3) between the two salt forms of thiamine are likely to be related to the differences in counterions. The presence of the additional $\mathrm{HCl}$ in $\mathrm{TClHCl}$ could have led to stronger and/or more extensive hydrogen bonding between $\mathrm{TClHCl}$ and the polymers compared to $\mathrm{TMN}$, as evident in the larger hydroxyl region peak shifts in the FTIR spectra of the TCIHCl:PEC dispersions [8] than the TMN:PEC dispersions (Figure 3A). The additional $\mathrm{HCl}$ in $\mathrm{TClHCl}$ also contributes to the much higher solubility of TClHCl compared to TMN (Table 3). This enhanced intermolecular interaction network between $\mathrm{TClHCl}$ and PEC compared to TMN and PEC likely contributed to the higher proportions of polymer necessary to amorphize TMN than TClHCl. Additionally, the $\mathrm{T}_{\mathrm{g}}$ values of TMN and TClHCl are 40 and $74{ }^{\circ} \mathrm{C}$, respectively, estimated using the Boyer-Beaman rule (Table 3); thus, more polymer was necessary to increase the $\mathrm{T}_{\mathrm{g}}$ of the TMN solid dispersions to the same extent as in the $\mathrm{TClHCl}$ solid dispersions. The difference in $\mathrm{T}_{\mathrm{g}}$ between the two salt forms may have also contributed to the higher proportions of polymer necessary to amorphize TMN than $\mathrm{TClHCl}$.

Table 3. Solid state property comparison between $\mathrm{TMN}$ and $\mathrm{TClHCl}$.

\begin{tabular}{c}
\hline \\
Structure \\
Molecular weight ${ }^{1}$ \\
Melting point ${ }^{1}$ \\
$\mathrm{~T}_{\mathrm{g}}{ }^{2}$
\end{tabular}

When comparing the physical stability of amorphous thiamine in solid dispersions with $95 \%$ polymer, PEC and PVP prevented crystallization of both $\mathrm{TMN}$ and $\mathrm{TClHCl}$ in the dispersions over the 8-week duration of the study when stored at $11 \% \mathrm{RH}$ and $30{ }^{\circ} \mathrm{C}-60^{\circ} \mathrm{C}$. In both $\mathrm{TMN}$ and $\mathrm{TClHCl}$ dispersions, less PEC was required to amorphize the vitamin and also better stabilized amorphous thiamine than PVP, indicating an advantage for interactions between thiamine and PEC compared to thiamine and PVP. The increased physical stability of thiamine in the presence of PEC also correlated to increased chemical stability when compared to PVP dispersions. Differences in physical stability of amorphous thiamine were related to the salt form of thiamine (counterion present), type of polymer, and amount of polymer present in the dispersion, mainly due to differences in the extent of hydrogen bonding between thiamine and the polymer.

\subsubsection{Chemical Stability}

Thiamine was more chemically stable in the crystalline state than in the amorphous state for both TMN and TClHCl physically blended or co-lyophilized with PEC or PVP. Increasing the storage RH to $75 \% \mathrm{RH}$, compared to $11 \% \mathrm{RH}$, increased the degradation of thiamine in physical mixtures of TMN or $\mathrm{TClHCl}$ blended with PVP, attributed to partial dissolution of the vitamin in the plasticized PVP matrix at this RH. Significantly more $(p<0.05)$ thiamine degraded in TMN blends than in TClHCl blends with 
PVP after 8 weeks of storage at $75 \% \mathrm{RH}$ and $40{ }^{\circ} \mathrm{C}(27 \%$ and $76 \%$ thiamine remaining, respectively). A contributing factor to the difference in thiamine loss between $\mathrm{TMN}$ and $\mathrm{TClHCl}$ in these systems could be attributed to differences in the pre-lyophilization $\mathrm{pH}$ of the samples, which were 5.2 and 3.8 in 5TMN:95PVP and 5TClHCl:95PVP solutions, respectively (in $10 \mathrm{~mL}$ of $\mathrm{H}_{2} \mathrm{O}$ at $25^{\circ} \mathrm{C}$ ). Thiamine is known to be much more stable in acidic conditions [2]. Although pre-lyophilization $\mathrm{pH}$ does not always correlate to $\mathrm{pH}$ of the dispersion [32], the role of $\mathrm{pH}$ is still worth considering. Voelker, Miller, Running, Taylor and Mauer [5] investigated TMN and $\mathrm{TClHCl}$ degradation in solutions, and due to the $\mathrm{pH}$ of solutions as a function of thiamine salt form resulting from differences in counterion in solution (similar to the pre-lyophilization $\mathrm{pHs}$ in the current study), thiamine was much more stable in solutions of $\mathrm{TClHCl}$ than TMN. No significant thiamine degradation occurred in $\mathrm{TClHCl}$ solutions stored at $40{ }^{\circ} \mathrm{C}$ for 174 days, but only $44-87 \%$ of thiamine (dependent on starting concentration) remained in TMN solutions after 63 days of storage at $40{ }^{\circ} \mathrm{C}$ [5].

This $\mathrm{pH}$-related trend in thiamine stability was also found in the amorphous solid dispersions of 5TMN:95PVP and 5TClHCl:95PVP stored at $75 \% \mathrm{RH}$ and $40{ }^{\circ} \mathrm{C}$, wherein significantly more thiamine degraded in 5TMN:95PVP dispersions than in 5TClHCl:95PVP dispersions $(7 \%$ and $68 \%$ thiamine remaining after 28 days of storage, respectively) (Figure $8 \mathrm{~A}$ ). As in the crystalline physical mixtures, the hygroscopic nature of PVP led to considerable moisture sorption in which hydration of both TMN and $\mathrm{TClHCl}$ occurred, and the differences in thiamine degradation between $\mathrm{TMN}$ and $\mathrm{TClHCl}$ in the amorphous solid dispersions were attributed to $\mathrm{pH}$ differences: less thiamine degraded in the more acidic systems containing $\mathrm{TClHCl}$ than in those containing TMN. The degradation pathway of thiamine differs as a function of $\mathrm{pH}$, and thus the degradation products formed in each condition also differ [5]. Differences in degradation peaks on HPLC chromatograms of degraded 5TMN:95PVP and 5TClHCl:95PVP samples indicate that degradation pathway may have differed between the two samples, which suggests that $\mathrm{pH}$ was potential factor for differences in stability between TMN and $\mathrm{TClHCl}$ in storage conditions that resulted in dissolved thiamine in the samples.

However, thiamine degradation did not significantly differ between the comparable formulations of TMN and $\mathrm{TClHCl}$ dispersions with PEC or PVP stored at $11 \% \mathrm{RH}$, where less vitamin hydration would have occurred (Figure 8B,C). When chemical stability of thiamine in $\mathrm{TMN}$ and $\mathrm{TClHCl}$ dispersions prepared with increasing ratios of PVP were compared in samples stored at $11 \% \mathrm{RH}$, thiamine stability and reaction kinetics in comparable formulations and storage conditions were fairly similar and most often not significantly different regardless of thiamine salt form. For example, in dispersions containing $99 \%$ PVP stored for 56 days at $11 \% \mathrm{RH}$ and $60{ }^{\circ} \mathrm{C}, 66 \%$ and $65 \%$ thiamine remained and $\mathrm{k}_{\text {obs }}=0.0055$ and 0.0062 day $^{-1}$ in TMN and TClHCl dispersions, respectively (Table 2). In general, both salt forms of thiamine had similar degradation behavior in the amorphous glassy solid state, and polymer type had the same impact on thiamine stability regardless of thiamine salt form.
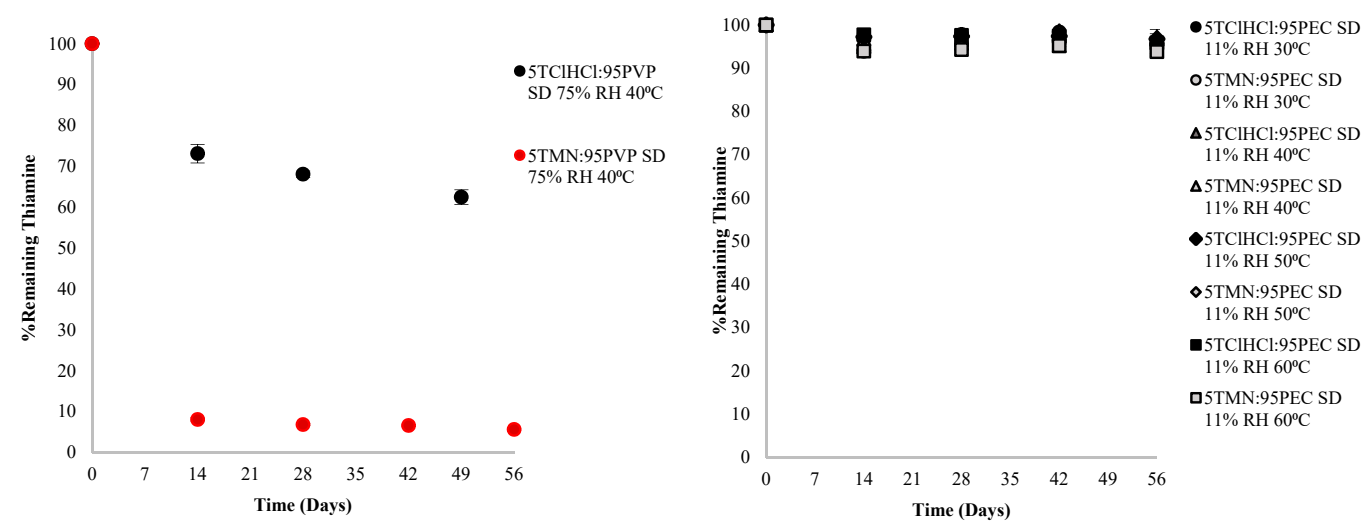

(A)

(B)

Figure 8. Cont. 


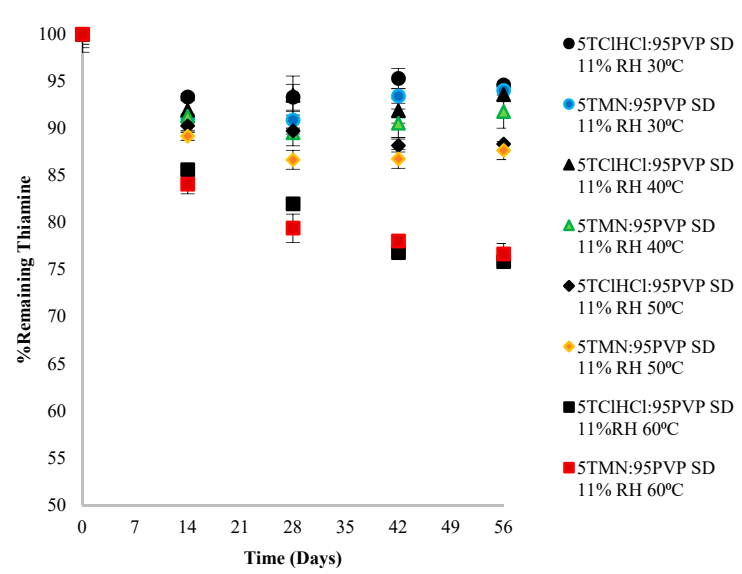

(C)

Figure 8. Comparison of chemical stability of $\mathrm{TMN}$ and $\mathrm{TClHCl}$ amorphous solid dispersions (SD) with $95 \%$ polymer: (A) SDs with 95\% PVP and stored at $75 \% \mathrm{RH}$ and $40{ }^{\circ} \mathrm{C}$; (B) SDs with $95 \%$ PEC and stored at $11 \% \mathrm{RH}$ and $30-60{ }^{\circ} \mathrm{C}$; and (C) SDs with 95\% PVP and stored at $11 \% \mathrm{RH}$ and $30-60{ }^{\circ} \mathrm{C}$.

\section{Materials and Methods}

\subsection{Materials}

Crystalline thiamine mononitrate (TMN) was purchased from Spectrum Chemical Mfg. Corp. (New Brunswick, NJ, USA). The polymers used in the study were pectin (PEC) from citrus peel with a $\sim 61 \%$ degree of esterification and polyvinylpyrrolidone (PVP) with a molecular weight of 40,000, both of which were purchased from Sigma-Aldrich Inc. (St. Louis, MO, USA). The RH conditions (reported here at $25^{\circ} \mathrm{C}$ ) were created in desiccators using saturated salt solutions of lithium chloride $(\mathrm{LiCl}, 11 \% \mathrm{RH})$ (EMD Millipore, Billerica, MA, USA) or sodium chloride ( $\mathrm{NaCl}, 75 \% \mathrm{RH}$ ) (Sigma-Aldrich Inc.). HPLC grade trifluoroacetic acid (TFA) was purchased from Sigma-Aldrich Inc., and acetonitrile was purchased from Fisher Scientific Co., LLC (Pittsburgh, PA, USA). A Barnstead E-Pure ultrapure water purification system (ThermoScientific, Waltham, MA, USA) with a resistivity of $\sim 17.5 \mathrm{M} \Omega \cdot \mathrm{cm}$ was used to deionize and purify all water used in this study.

\subsection{Preparations of TMN Solid Dispersions via Lyophilization}

TMN:polymer dispersions were prepared by lyophilization using our previously reported method $[8,10]$. First, $100 \mathrm{mg}$ total solid content was dissolved in $10 \mathrm{~mL}$ of deionized water $(\mathrm{w} / \mathrm{v})$. To investigate the effect of vitamin proportion on physical and chemical stability, 14 different mass ratios of TMN to polymer (both PEC and PVP) (1\%, 3\%, 5\%, 7\%, 10\%, 20\%, 30\%, 40\%, 50\%, 60\%, 70\%, 80\%, 90\%, and $100 \%$ TMN) were prepared by varying the TMN:polymer ratios while maintaining the total solids content at $100 \mathrm{mg}$. All the samples were prepared in triplicate. TMN:polymer solutions were mixed with a Roto-Shake Genie ${ }^{\circledR}$ SI-1100 (Scientific Industries, Inc., Bohemia, NY, USA) for $10 \mathrm{~min}$. The pHs of the solutions were measured with an Orion Star A211 pH meter (ThermoScientific Inc.). The solutions were then frozen overnight at $-20^{\circ} \mathrm{C}$ prior to lyophilization. Frozen samples were then loaded into a VirTis Genesis 25ES shelf freeze dryer (SP Scientific, Stone Ridge, NY, USA). Initially, samples were frozen for $6 \mathrm{~h}$ at $-40{ }^{\circ} \mathrm{C}$ and $300 \mathrm{mTorr}$. Then, the first drying step was initiated in order to remove the bulk of water via sublimation at $-40^{\circ} \mathrm{C}$ by maintaining the vacuum at $150 \mathrm{mTorr}$ for $24 \mathrm{~h}$ (primary drying). In the secondary drying step, samples were held for $9 \mathrm{~h}$ at each step in $10^{\circ} \mathrm{C}$ intervals from -40 to $20^{\circ} \mathrm{C}$. Finally, the samples were held at $25^{\circ} \mathrm{C}$ and 300 mTorr for $6 \mathrm{~h}$. Immediately after the freeze-drying cycle was complete, samples were placed into the RH-controlled desiccators. 


\subsection{Storage Treatments}

Samples were stored in desiccators at select temperature and RH conditions. Four different temperatures at the same $\mathrm{RH}$ were chosen for the purpose of calculating reaction kinetics of thiamine degradation: $11 \% \mathrm{RH}$ and $30,40,50$ and $60^{\circ} \mathrm{C}$. In addition to these conditions, a higher storage $\mathrm{RH}$ $(75 \%)$ at two different temperatures $\left(25\right.$ and $\left.40{ }^{\circ} \mathrm{C}\right)$ was selected to investigate the effect of high $\mathrm{RH}$ on thiamine degradation. Saturated salt solutions were used to control the RH in desiccators, and RH values were verified by an AquaLab 4TE water activity meter (Decagon Devices Inc., Pullman, WA, USA). Temperature conditions were controlled by using water jacketed incubators (Forma Scientific, Inc., Marietta, OH, USA) in which the desiccators were placed. Samples were stored for up to eight weeks, with a subset removed biweekly for HPLC analysis. This subset was then discarded after analysis.

\subsection{Powder X-ray Diffraction (PXRD)}

A Rigaku Smartlab ${ }^{\mathrm{TM}}$ diffractometer (Rigaku Americas, TX, USA) equipped with a $\mathrm{Cu}-\mathrm{K} \alpha$ radiation source and D/tex ultra-detector was used to analyze the physical structure of the starting ingredients and initial solid dispersions. Additionally, TMN:polymer solid dispersions stored at select conditions were analyzed over time. Scans were generated between 5 and $40^{\circ} 2 \theta$ with an increment of $0.02^{\circ}$ and a rate of $4^{\circ}$ per min. Structural distinction between amorphous and crystalline TMN was determined based on the PXRD patterns. Samples that exhibited a diffuse halo were considered to be PXRD amorphous, while samples in which sharp peaks greater than two standard deviations above the baseline were observed on the diffractogram were labeled as crystalline.

\subsection{Fourier Transform Infrared Spectroscopy (FTIR)}

Samples were analyzed by FTIR to determine the presence and extent of hydrogen bonding and intermolecular interactions between thiamine and the polymer in the solid dispersions. A Nexus 670 FTIR spectrometer (ThermoNicolet, Madison, WI, USA) equipped with an MCTA detector and a DRIFTS Avatar Diffuse Reflectance Smart Accessory (ThermoElectron Corp., Madison, WI, USA) was used to collect FTIR spectra of samples, as previously described by Arioglu-Tuncil, Bhardwaj, Taylor and Mauer [8]. The spectra of samples were analyzed using OMNIC software (ThermoElectron Corp.).

\subsection{Chemical Stability Determination with HPLC}

A Waters 2690SM (Waters Corp., Milford, MA, USA) HPLC with a Waters Xselect HSS T3 (3.5 $\mu \mathrm{m}$, $4.6 \times 100 \mathrm{~mm}$ ) column and a Waters 2996 photodiode array detector were used for thiamine quantification in samples containing crystalline TMN, physical blends of crystalline TMN with polymers, and thiamine: polymer solid dispersions. The amount of thiamine remaining was quantified by the standard curve prepared at a concentration range $0.005-1 \mathrm{mg} / \mathrm{mL}$ prior to analysis $\left(\mathrm{r}^{2}=0.9997-1.0000\right)$. Samples were diluted with solvent to a final thiamine concentration of $0.25-0.5 \mathrm{mg} / \mathrm{mL}$ and filtered through a $0.2 \mu \mathrm{m}$ syringe filter. Acetonitrile (solvent A) and water with $0.1 \%$ TFA (solvent B) were used as mobile phases. The following gradient method was adapted from Xia, et al. [33] and performed as follows: 0/100 at $0 \mathrm{~min}$ (immediate), 3/97 at $4 \mathrm{~min}$ (linear), 10/90 at $6 \mathrm{~min}$ (linear), 0/100 $10 \mathrm{~min}$ (linear), and 0/100 from 10 to $15 \mathrm{~min}$ (immediate). The flow rate and the injection volume used were $1 \mathrm{~mL} / \mathrm{min}$ and $10 \mu \mathrm{L}$, respectively. Samples were scanned between $235-400 \mathrm{~nm}$, and the integration was conducted at $254 \mathrm{~nm}$ using Masslynx V4.1 software (Waters Corp.).

\subsection{Moisture Sorption Isotherm Analysis}

A SPSx-1 $\mu$ Dynamic Vapor Sorption Analyzer (Project Messtechnik, Ulm, Germany) was used to obtain moisture sorption profiles of individual ingredients and solid dispersions with $95 \%$ polymer. Samples (100-300 mg) were loaded into aluminum pans in a 24-ring sample holder. Equilibrium criteria and maximum step time were set at a weight change of $0.001 \%$ in $30 \mathrm{~min}$ and $12 \mathrm{~h}$, respectively. 
Samples were first equilibrated at $0 \% \mathrm{RH}$ for $12 \mathrm{~h}$ and then analyzed from $5 \%$ to $95 \% \mathrm{RH}$ at $25{ }^{\circ} \mathrm{C}$ with a 5\% RH step size. All samples were measured in duplicate.

\subsection{Determination of Glass Transition Temperature by Differential Scanning Calorimetry (DSC)}

Thermal analyses of the samples were conducted using a Discovery DSC equipped with a refrigerated cooling accessory (TA Instruments, New Castle, DE, USA). Nitrogen served as the purge gas at a rate of $50 \mathrm{~mL} / \mathrm{min}$. Approximately $7-12 \mathrm{mg}$ of sample was weighed and hermetically sealed into Tzero pans (TA Instruments). Samples were heated from $-20^{\circ} \mathrm{C}$ to a temperature $20-30{ }^{\circ} \mathrm{C}$ higher than the expected $\mathrm{T}_{\mathrm{g}}$ values at a rate of $20^{\circ} \mathrm{C} / \mathrm{min}$, followed by cooling to $-20^{\circ} \mathrm{C}$ at a rate of $10^{\circ} \mathrm{C} / \mathrm{min}$. Then, the second heating scan was applied to $150{ }^{\circ} \mathrm{C}$ at $20^{\circ} \mathrm{C} / \mathrm{min}$. $\mathrm{T}_{\mathrm{g}}$ was determined in this second heating step (where a baseline shift occurred in the endothermic direction) using TRIOS software.

\subsection{Reaction Kinetics Calculations}

Thiamine has been observed to follow first order or pseudo-first order reaction kinetics $[5,7,27,34]$. Experimental data were fitted to the following equation to calculate reaction rate constants:

$$
\ln \frac{x}{x_{0}}=-k t
$$

where $x$ corresponds to thiamine concentration at time $t$ (days), $x_{0}$ is the initial thiamine concentration, and $k$ is the reaction rate constant $\left(\right.$ days $\left.^{-1}\right)$. The value of $t_{90}$, the time at which $90 \%$ of the initial concentration of thiamine remains, was evaluated using the following equation:

$$
t_{90}=\frac{\ln (0.9)}{-k}
$$

where $k$ is the reaction rate constant $\left(\right.$ days $\left.^{-1}\right)$.

\subsection{Statistical Analysis}

All analyses were performed in triplicate, unless otherwise noted, and data are presented as mean \pm standard deviation. SAS Software Version 9.4 (SAS Institute, Cary, NC, USA) was used to conduct statistical analyses. Analysis of variance (ANOVA) was performed at $\alpha=0.05$ significance level to determine differences among the samples and controls. Tukey's multiple comparison test $(\alpha=0.05)$ was used to test whether the samples were statistically different.

\section{Conclusions}

Amorphization of TMN was achieved when at least $80 \%$ of PEC or $90 \%$ of PVP were used in the dispersion formulations, and both polymers were effective at inhibiting TMN crystallization in the solid dispersions stored at $11 \% \mathrm{RH}\left(30-60^{\circ} \mathrm{C}\right)$ for the entirety of the 8-week study. At a higher storage RH (75\%RH), PEC inhibited the crystallization of TMN in the initially amorphous solid dispersions, but the higher moisture sorption in the PVP dispersions led to hydration of the TMN. While no significant thiamine loss was found in crystalline TMN, thiamine degradation was accelerated when thiamine was in the amorphous form, and further accelerated when the TMN dissolved in the polymer matrix. Thiamine was less labile in PEC dispersions than in PVP dispersions, attributed to the greater stabilizing effects of noncovalent intermolecular interactions between the PEC and TMN and the more acidic nature of the PEC polymer. Comparing the physical and chemical stability of thiamine from the two most common ingredient salt forms of the vitamin used in food and pharmaceutical ingredients (TMN and $\mathrm{TClHCl}$ ) led to the following understanding of counterion and polymer co-formulation effects on thiamine stability in dispersions: 
- Thiamine was less stable when present at low proportions in a solid dispersion than when present at higher proportions (a concerning factor when delivering low concentrations of thiamine in solid formulations, and an indicator that the sample $\mathrm{T}_{\mathrm{g}}$ is not the main factor in governing thiamine stability in amorphous systems since the thiamine was most labile in the dispersions with the highest $\mathrm{T}_{\mathrm{gs}}$ );

- Thiamine was most stable in the crystalline form, less stable in the amorphous form, and degraded most rapidly when present in (concentrated) solutions (such as in the physical mixtures and dispersions of TMN with PVP that were stored at $75 \% \mathrm{RH}$ and $40^{\circ} \mathrm{C}$ );

- Despite the higher solubility of $\mathrm{TClHCl}$ compared to $\mathrm{TMN}$, thiamine was more stable in the amorphous vitamin:polymer dispersions made with $\mathrm{TClHCl}$ than with TMN. The enhanced stability of thiamine in the TClHCl:polymer dispersions was attributed to not only the increased noncovalent intermolecular interactions between the $\mathrm{TClHCl}$ and polymer compared to the TMN-polymer interactions ( $\mathrm{TClHCl}$ has an additional hydrogen bond donor), but also to the more acidic $\mathrm{pHs}$ created by the $\mathrm{HCl}$ counterion than the nitrate counterion.

TMN is the more common ingredient form of thiamine used to fortify or enrich solid products. While thiamine degrades via different $\mathrm{pH}$-dependent pathways, which should be explored when considering formulations for delivering thiamine in foods and dietary supplements given not only the need to deliver the amount of vitamin claimed on the label but also the possible sensory-related impacts of thiamine degradation, the finding that thiamine was more stable in $\mathrm{TClHCl}$ :polymer solid dispersions than in TMN:polymer solid dispersions supports the consideration of using TClHCl instead of TMN as the form of thiamine in products wherein the vitamin is present in the final formulation in amorphous form.

Author Contributions: Conceptualization, L.J.M. and L.S.T.; methodology, S.A.-T., L.J.M. and L.S.T.; validation, S.A.-T. and A.L.V.; formal analysis, S.A.-T. and A.L.V.; investigation, S.A.-T.; resources, L.J.M.; writing一 original draft preparation, S.A.-T. and A.L.V.; writing-review and editing, S.A.-T., A.L.V., L.J.M. and L.S.T.; visualization, S.A.-T. and A.L.V.; supervision, L.J.M.; project administration, L.J.M. and L.S.T.; funding acquisition, L.J.M. and L.S.T. All authors have read and agreed to the published version of the manuscript.

Funding: This work was funded by USDA [grant number 2016-67017-24592]. Seda Arioglu-Tuncil was a recipient of fellowship from the Ministry of National Education, Republic of Turkey.

Conflicts of Interest: The authors declare no conflict of interest.

$\begin{array}{ll}\text { Abbreviations } \\ \text { DSC } & \text { Differential scanning calorimetry } \\ \text { FTIR } & \text { Fourier Transform infrared spectroscopy } \\ \text { HBA } & \text { Hydrogen bond acceptor } \\ \text { HBD } & \text { Hydrogen bond donor } \\ \text { HPLC } & \text { High-performance liquid chromatography } \\ \text { PEC } & \text { Pectin } \\ \text { PM } & \text { Physical mixture } \\ \text { PVP } & \text { Poly(vinylpyrrolidone) } \\ \text { PXRD } & \text { Powder X-ray diffraction } \\ \text { RH } & \text { Relative humidity } \\ \text { SD } & \text { Solid dispersion } \\ \text { TClHCl } & \text { Thiamine chloride hydrochloride } \\ \text { TMN } & \text { Thiamine mononitrate } \\ \text { TFA } & \text { Trifluoroacetic acid } \\ T_{g} & \text { Glass transition temperature }\end{array}$




\section{References}

1. Mulley, E.; Stumbo, C.; Hunting, W. Kinetics of thiamine degradation by heat. Effect of $\mathrm{pH}$ and form of the vitamin on its rate of destruction. J. Food Sci. 1975, 40, 989-992. [CrossRef]

2. Dwivedi, B.K.; Arnold, R.G. Chemistry of thiamine degradation in food products and model systems: A review. J. Agric. Food. Chem. 1973, 21, 54-60. [CrossRef] [PubMed]

3. Farrer, K. The thermal destruction of vitamin B1 in foods. Adv. Food Res. 1955, 6, 257-311. [CrossRef]

4. Grosch, W.; Zeiler-Hilgart, G. Formation of Meatlike Flavor Compounds. In Flavor Precursors; American Chemical Society: Washington, DC, USA, 1992; Volume 490, pp. 183-192.

5. Voelker, A.L.; Miller, J.; Running, C.A.; Taylor, L.S.; Mauer, L.J. Chemical stability and reaction kinetics of two thiamine salts (thiamine mononitrate and thiamine chloride hydrochloride) in solution. Food Res. Int. 2018, 112, 443-456. [CrossRef] [PubMed]

6. Dreher, J.G.; Rouseff, R.L.; Naim, M. GC-olfactometric characterization of aroma volatiles from the thermal degradation of thiamin in model orange juice. J. Agric. Food Chem. 2003, 51, 3097-3102. [CrossRef] [PubMed]

7. Labuza, T.; Kamman, J. Comparison of stability of thiamin salts at high temperature and water activity. J. Food Sci. 1982, 47, 664-665. [CrossRef]

8. Arioglu-Tuncil, S.; Bhardwaj, V.; Taylor, L.S.; Mauer, L.J. Amorphization of thiamine chloride hydrochloride: A study of the crystallization inhibitor properties of different polymers in thiamine chloride hydrochloride amorphous solid dispersions. Food Res. Int. 2017, 99, 363-374. [CrossRef] [PubMed]

9. Hancock, B.C.; Zografi, G. Characteristics and significance of the amorphous state in pharmaceutical systems. J. Pharm. Sci. 1997, 86, 1-12. [CrossRef]

10. Arioglu-Tuncil, S.; Voelker, A.L.; Taylor, L.S.; Mauer, L.J. Amorphization of thiamine chloride hydrochloride: Effects of physical state and polymer type on the chemical stability of thiamine in solid dispersions. Int. J. Mol. Sci. 2020, 21, 5935. [CrossRef]

11. Christina, B.; Taylor, L.S.; Mauer, L.J. Physical stability of 1-ascorbic acid amorphous solid dispersions in different polymers: A study of polymer crystallization inhibitor properties. Food Res. Int. 2015, 76, 867-877. [CrossRef]

12. Wegiel, L.A.; Zhao, Y.; Mauer, L.J.; Edgar, K.J.; Taylor, L.S. Curcumin amorphous solid dispersions: The influence of intra and intermolecular bonding on physical stability. Pharm. Dev. Technol. 2014, 19, 976-986. [CrossRef] [PubMed]

13. Miyazaki, T.; Yoshioka, S.; Aso, Y.; Kojima, S. Ability of polyvinylpyrrolidone and polyacrylic acid to inhibit the crystallization of amorphous acetaminophen. J. Pharm. Sci. 2004, 93, 2710-2717. [CrossRef] [PubMed]

14. Kestur, U.S.; Van Eerdenbrugh, B.; Taylor, L.S. Influence of polymer chemistry on crystal growth inhibition of two chemically diverse organic molecules. CrystEngComm 2011, 13, 6712-6718. [CrossRef]

15. Wang, R.; Pellerin, C.; Lebel, O. Role of hydrogen bonding in the formation of glasses by small molecules: A triazine case study. J. Mater. Chem. 2009, 19, 2747-2753. [CrossRef]

16. Roos, Y.H.; Drusch, S. Reaction kinetics. In Phase Transitions in Foods, 2nd ed.; Academic Press: San Diego, CA, USA, 2016; pp. 275-313. [CrossRef]

17. Ismail, Y.; Mauer, L.J. Phase transitions of ascorbic acid and sodium ascorbate in a polymer matrix and effects on vitamin degradation. J. Food Process. Eng. 2019, 43, e13073. [CrossRef]

18. Bell, L.; White, K. Thiamin stability in solids as affected by the glass transition. J. Food Sci. 2000, 65, 498-501. [CrossRef]

19. Slade, L.; Levine, H. Beyond water activity: Recent advances based on an alternative approach to the assessment of food quality and safety. Crit. Rev. Food Sci. Nutr. 1991, 30, 115-360. [CrossRef]

20. Beaman, G. Relation between (apparent) second-order transition temperature and melting point. J. Polym. Sci. 1952, 9, 470-472. [CrossRef]

21. Fox, T.G. Influence of diluent and of copolymer composition on the glass temperature of a polymer system. Bull. Am. Phys. Soc. 1956, 1, 123-135.

22. Gordon, M.; Taylor, J.S. Ideal copolymers and the second-order transitions of synthetic rubbers. I. Noncrystalline copolymers. Rubber Chem. Technol. 1953, 26, 323-335. [CrossRef]

23. Bell, L.; Hageman, M.J. Differentiating between the effects of water activity and glass transition dependent mobility on a solid state chemical reaction: Aspartame degradation. J. Agric. Food. Chem. 1994, 42, 2398-2401. [CrossRef] 
24. Sanchez, J.; Ismail, Y.; Christina, B.; Mauer, L.J. Degradation of L-ascorbic acid in the amorphous solid state. J. Food Sci. 2018, 83, 670-681. [CrossRef] [PubMed]

25. Lai, M.C.; Hageman, M.J.; Schowen, R.L.; Borchardt, R.T.; Topp, E.M. Chemical stability of peptides in polymers. 1. Effect of water on peptide deamidation in poly(vinyl alcohol) and poly(vinyl pyrrolidone) matrixes. J. Pharm. Sci. 1999, 88, 1073-1080. [CrossRef]

26. Luthra, S.A.; Shalaev, E.Y.; Medek, A.; Hong, J.; Pikal, M.J. Chemical stability of amorphous materials: Specific and general media effects in the role of water in the degradation of freeze-dried zoniporide. J. Pharm. Sci. 2012, 101, 3110-3123. [CrossRef] [PubMed]

27. Pachapurkar, D.; Bell, L. Kinetics of thiamin degradation in solutions under ambient storage conditions. J. Food Sci. 2006, 70, c423-c426. [CrossRef]

28. Waterman, K.C.; Gerst, P.; Dai, Z. A generalized relation for solid-state drug stability as a function of excipient dilution: Temperature-independent behavior. J. Pharm. Sci. 2012, 101, 4170-4177. [CrossRef] [PubMed]

29. David, S.; Timmins, P.; Conway, B. Impact of the counterion on the solubility and physicochemical properties of salts of carboxylic acid drugs. Drug Dev. Ind. Pharm. 2012, 38, 93-103. [CrossRef]

30. ChemSpider. Thiamine; Royal Society of Chemistry: London, UK, 2015.

31. Hiatt, A.N.; Ferruzzi, M.G.; Taylor, L.S.; Mauer, L.J. Impact of deliquescence on the chemical stability of vitamins B(1), B(6), and C in powder blends. J. Agric. Food. Chem. 2008, 56, 6471-6479. [CrossRef]

32. Murase, N.; Franks, F. Salt precipitation during the freeze-concentration of phosphate buffer solutions. Biophys. Chem. 1989, 34, 293. [CrossRef]

33. Xia, F.; Hong, P.; Alden, B.; Boissel, C.; Swanson, D.; Chambers, E.; Diehl, D.; Iraneta, P.; Mazzeo, J.; Wyndham, K.; et al. Improvements in reversed-phase HPLC columns designed for polar compound retention. In Proceedings of the HPLC, San Francisco, CA, USA, 17-23 June 2006.

34. Windheuser, J.J.; Higuchi, T. Kinetics of thiamine hydrolysis. J. Pharm. Sci. 1962, 51, 354-364. [CrossRef]

Publisher's Note: MDPI stays neutral with regard to jurisdictional claims in published maps and institutional affiliations.

(C) 2020 by the authors. Licensee MDPI, Basel, Switzerland. This article is an open access article distributed under the terms and conditions of the Creative Commons Attribution (CC BY) license (http://creativecommons.org/licenses/by/4.0/). 